\title{
Non-Alcoholic Steatohepatitis: Clinical and Translational Research
}

\author{
Manuela G. Neuman ${ }^{1,2,3,4}$, Mihai Voiculescu ${ }^{3,4,5}$, Radu M. Nanau ${ }^{1}$, Yaakov Maor ${ }^{6}$, Ehud Melzer ${ }^{6}$, Lawrence B. Cohen ${ }^{7}$, \\ Mihai Opris ${ }^{1}$ Stephen Malnick ${ }^{6}$ \\ ${ }^{1}$ In Vitro Drug Safety and Biotechnology, Toronto, Canada; ${ }^{2}$ Department of Pharmacology and Toxicology, Faculty of \\ Medicine, University of Toronto, Toronto, Canada; ${ }^{3}$ Division of Nephrology and Internal Medicine, Fundeni Clinical \\ Institute and ${ }^{4}$ University of Medicine and Pharmacy, "Carol Davila", Bucharest, Romania; 5 Medical Clinic II and \\ Gastroenterology, University Hospital Bucharest, Bucharest, Romania; ${ }^{6}$ Division of Gastroenterology, Kaplan Health \\ Sciences Centre, Department of Medicine, Faculty of Medicine, Hebrew University, Rehovot, Israel; ${ }^{7}$ Division of \\ Gastroenterology, Sunnybrook Health Sciences Centre and Department of Internal Medicine, University of Toronto, \\ Toronto, Canada.
}

Received, September 28, 2015; Revised, December 12, 2015; Accepted, January 1, 2016; Published, January 11, 2016

\begin{abstract}
The present review includes translational and clinical research that characterize non-alcoholic fatty liver disease (NAFLD) and non-alcoholic steatohepatitis (NASH). Clinical and experimental evidence led to the recognition of the key toxic role played by lipotoxicity in the pathogenesis of NAFLD. The current understanding of lipotoxicity suggests that organ injury is initiated by the generation of oxidative metabolites and the translocation of gut-derived endotoxin. These processes lead to cellular injury and stimulation of the inflammatory responses mediated through a variety of molecules. The injury progresses through impairment of tissue regeneration and extracellular matrix turnover, leading to fibrogenesis and cirrhosis. Several cell types are involved in this process, predominantly stellate cells, macrophages and parenchymal cells. In response to inflammation, cytokines activate many signaling cascades that regulate fibrogenesis. This examination brings together research focusing on the underlying mechanisms of injury. It highlights the various processes and molecules that are likely involved in inflammation, immune modulation, and fibrogenesis in the liver. We searched electronic databases (Medline, Embase) for this review. This integrative work investigates different aspects of liver damage and possible repair. We aim to (1) determine the immuno-pathology of liver damage due to steatosis, (2) suggest diagnostic markers of NASH, (3) examine the role of behaviour in the development of $\mathrm{NASH}$, and (4) develop common tools to study steatosis-induced effects in clinical studies. Special accent is put on co-morbidities with renal and neuropsychological disorders. Moreover, we review the evidence in literature on the role of moderate alcohol consumption in individuals that present NAFLD/NASH.

Key Words: behavior, diet, imaging, non-alcoholic fatty liver, nonalcoholic steatohepatitis, laboratory markers.
\end{abstract}

This article is open to POST-PUBLICATION REVIEW. Registered readers (see "For Readers") may comment by clicking on ABSTRACT on the issue's contents page.

\author{
ABBREVIATIONS \\ ALT - alanine aminotransferase \\ APRI - aspartate aminotransferase-to-platelet ratio index \\ ARFI - acoustic radiation force impulse \\ AST - aspartate aminotransferase \\ AT - aerobic training \\ BAAT - BMI, age, ALT, triglyceride \\ BARD - BMI, AST/ALT ratio, diabetes \\ BMI - body mass index \\ CKD - chronic kidney disease \\ $\mathrm{CI}$ - confidence interval \\ hsCRP - high-sensitivity C-reactive protein \\ eGFR - estimated glomerular filtration rate \\ $\gamma$-GTP - gamma-glutamyl transpeptidase \\ IL - interleukin \\ LPS - lipopolysaccharide
}

\author{
MRI - magnetic resonance imaging \\ MS - metabolic syndrome \\ NAFLD - non-alcoholic fatty liver disease \\ $\mathrm{NASH}$ - non-alcoholic steatohepatitis \\ NPV - negative predictive value \\ OR - odds ratio \\ PPV - positive predictive value \\ RT - resistance training \\ TNF - tumor necrosis factor
}

Correspondence Author: Manuela G. Neuman, Ph.D., Dept. of Pharmacology and Toxicology, Faculty of Medicine, University of Toronto; In Vitro Drug Safety and Biotechnology, Banting Institute, 100 College Street, Lab 217, Toronto, Ontario, Canada, M5G 0A3. Tel: 416-398-4880; Email: manuela.neuman@utoronto.ca 


\section{INTRODUCTION}

Non-alcoholic fatty liver disease (NAFLD) may be the most prevalent form of liver disease in developed countries. NAFLD can be diagnosed by imaging, histology, or both (1). NAFLD, per definition, requires an evidence of hepatic lipid deposition that is shown either by imaging or by histology. Moreover, the hepatic fat accumulation should not be a consequence of significant alcohol consumption, use of steatogenic medication or hereditary disorders. Morphologically, NAFLD is categorized into simple steatosis and non-alcoholic steatohepatitis (NASH). From the histological point of view, simple steatosis lesions are characterized only by fat droplets in hepatocytes, with no evidence of hepatocytes ballooning. In the biopsy of a NASH patient, the presence of steatosis is accompanied by lobular inflammation, portal granulocytic inflammation, Mallory-Denk bodies, satellitosis, acute cholestasis, perisinusoidal fibrosis, sclerosing hyaline necrosis, and venoocclusive disease, with or without hepatic fibrosis or cirrhosis $(2,3)$. Histological changes in the NASH liver are nearly identical to those induced by excessive alcohol intake, as seen in patients with alcoholic steatohepatitis (4).

In the majority of patients, NAFLD is associated with metabolic risk factors such as obesity, metabolic syndrome (MS), diabetes mellitus, and dyslipidemia. Adler and Scheffer (5) illustrated fatty liver leading to cirrhosis in obese individuals. Ludwig et al. (6) described hepatic abnormalities reflected by biochemical tests that are hardly to be confused with the marked hepatic abnormality and jaundice which some oral hypoglycemic agents can produce. The main abnormalities attributable to diabetes are the steatosis and the non-alcoholic steatohepatitis or "pseudoalcoholic liver disease". Since there is a hepatic injury attributed to oral hypoglycemics (7), Zimmerman and Ishak (8) argued that NASH lesions can be readily distinguished from hepatotoxic drug-induced lesions. Although risk factors for NASH include obesity, insulin-resistance and male gender, the disease can occur in patients of any race, gender or body weight. The recurrence of NASH in liver-transplant recipients implicates systemic host factors, rather than liver-related factors, in the development of the disease.
Imaging Methods and Non-invasive Tests Used to Stage Steatosis and Fibrosis

The liver biopsy can confirm the etiology of NASH and can assess structural alterations of cells and their organelles, as well as inflammatory activity and the degree of liver fibrosis. However, imaging has an important role in diagnosis. Non-invasive tests and imaging methods used to diagnose NAFLD/NASH are described in Table 1 (9-15). BAAT is a clinico-biological score combining body mass index (BMI), age at liver biopsy, alanine aminotransferase (ALT) and serum triglycerides, and is calculated according to the sum of BMI ( $\geq 28$ $=1,<28=0)$, age at liver biopsy $(\geq 50$ years $=1$, $<50=0)$, ALT $(\geq 2 \mathrm{~N}=1,<2 \mathrm{~N}=0)$, and serum triglycerides $(\geq 1.7 \mathrm{mmol} / \mathrm{L}=1,<1.7=0)$. The BAAT score can separate individuals without septal fibrosis, and thus identify those patients who will benefit the most from a liver biopsy. The NAFLD Fibrosis Score is also a tool that can render a liver biopsy unnecessary in a large proportion of NAFLD patients, as it can non-invasively characterize these individuals based on the presence or absence of advanced fibrosis. The NAFLD Fibrosis Score combines age, hyperglycemia, BMI, platelet count, albumin and the aspartate aminotransferase (AST)/ALT ratio, according to the formula of $1.675+0.037 \times$ age $($ years $)+0.094 \times$ BMI $\left(\mathrm{kg} / \mathrm{m}^{2}\right)$ $+1.13 \times$ impaired fasting glucose/diabetes (yes $=1$, no $=0)+0.99 \times$ AST/ALT ratio $(9)$.

FIB-4 is an example of an inexpensive and accurate test that can be used to assess fibrosis (16). Commercially available algorithms use routine biochemical parameters obtained from laboratory medicine to identify changes. An example is FibroTest, which can be used to assess liver fibrosis progression, permitting investigators to identify those individuals in need of a liver biopsy (17). NashTest uses an algorithm combining the 13 parameters of age, sex, height and weight, and serum levels of triglycerides, cholesterol, $\alpha 2$ macroglobulin, apolipoprotein A1, haptoglobin, gamma-glutamyl transpeptidase $(\gamma$-GTP), ALT, AST and total bilirubin (10). When compared with non-diseased patients, NASH patients were older, with higher weight, had higher levels of $\alpha 2$ macroglobulin, ALT, AST, glucose and triglycerides, had lower levels of $\gamma$-GTP, as well as higher fibrosis and steatosis stages as assessed by FibroTest and SteatoTest (10). 
Table 1: Imaging Methods

\begin{tabular}{|c|c|}
\hline Reference and Population & Associations \\
\hline $\begin{array}{l}9 \\
733 \text { patients with biopsy-proven NAFLD } \\
(480 \text { in construct cohort and } 253 \text { in } \\
\text { validation cohort })\end{array}$ & $\begin{array}{l}\text { NAFLD Fibrosis Score: }>0.676 \text { corresponds to negative result, } \\
<1.455 \text { to }>0.676 \text { corresponds to indeterminate result, and } \\
<1.455 \text { corresponds to positive result for advanced fibrosis }\end{array}$ \\
\hline $\begin{array}{l}10 \\
160 \text { NAFLD patients in a training group } \\
(57 \text { with no NASH, } 75 \text { with borderline } \\
\text { NASH and } 28 \text { with NASH) } \\
97 \text { NAFLD patients in a validation group } \\
\text { (41 with no NASH, } 21 \text { with borderline } \\
\text { NASH and } 35 \text { with NASH); } 383 \text { controls }\end{array}$ & $\begin{array}{l}\text { NashTest for the diagnosis of NASH: } 33 \% \text { sensitivity, } 94 \% \\
\text { sensitivity, } 66 \% \text { PPV and } 81 \% \text { NPV } \\
\text { NashTest for the diagnosis of borderline NASH or NASH: } 88 \% \\
\text { sensitivity, } 50 \% \text { sensitivity, } 74 \% \text { PPV and } 72 \% \text { NPV }\end{array}$ \\
\hline $\begin{array}{l}11 \\
172 \text { NAFLD patients }\end{array}$ & $\begin{array}{l}\text { ARFI shear wave imaging: } 90 \% \text { sensitivity and } 90 \% \text { specificity } \\
\text { to distinguish low (stage 0-2) from high (stage 3-4) fibrosis } \\
\text { stages at threshold of liver shear stiffness of } 4.24 \mathrm{kPa}\end{array}$ \\
\hline $\begin{array}{l}12 \\
117 \text { patients with biopsy-proven NAFLD }\end{array}$ & $\begin{array}{l}\text { 2D MRI: } 86 \% \text { sensitivity, } 91 \% \text { specificity, } 68 \% \text { PPV and } 97 \% \\
\text { NPV to discriminate advanced fibrosis (stage } 3-4 \text { ) from low } \\
\text { fibrosis (stage } 0-2 \text { ) at cut-off } 3.63 \mathrm{kPa}\end{array}$ \\
\hline $\begin{array}{l}13 \\
80 \text { consecutive patients with biopsy-proven } \\
\text { NAFLD ( } 70 \text { with NASH and } 10 \text { without } \\
\text { NASH; } 33 \text { with fibrosis stage } 0,25 \text { with } \\
\text { fibrosis stage } 1,10 \text { with fibrosis stage } 2,6 \\
\text { with fibrosis stage } 3 \text { and } 6 \text { with fibrosis } \\
\text { stage 4) }\end{array}$ & $\begin{array}{l}\text { 3D MRI: } 83 \% \text { raw sensitivity, } 80 \% \text { specificity, } 97 \% \text { PPV and } \\
40 \% \text { NPV for separating NASH from no NASH at cut-off }>1.5 \\
\text { kPa } \\
\text { 3D MRI: } 100 \% \text { raw sensitivity, } 93 \% \text { specificity, } 71 \% \text { PPV and } \\
100 \% \mathrm{NPV} \text { for separating NASH from no NASH at cut-off } \\
>2.43 \mathrm{kPa}\end{array}$ \\
\hline $\begin{array}{l}14 \\
76 \text { obese adolescents } \\
36 \text { lean adolescents }\end{array}$ & $\begin{array}{l}\text { APRI: } 0.149 \pm 0.038 \text { in lean, } 0.200 \pm 0.075 \text { in non-NAFLD } \\
\text { obese }(p<0.05 \text { vs. leans }) \text { and } 0.342 \pm 0.073 \text { in NAFLD obese } \\
(p<0.05 \text { vs. non-NAFLD obese })\end{array}$ \\
\hline $\begin{array}{l}15 \\
827 \text { NAFLD patients }\end{array}$ & $\begin{array}{l}\text { AST/ALT ratio } \geq 0.8: \text { OR } 8.2,95 \% \text { CI } 5.2-12.9 \text { for advanced } \\
\text { fibrosis } \\
\text { Diabetes mellitus: OR 2.8, 95\% CI 1.8-4.3 for advanced fibrosis } \\
\text { BMI } \geq 28: \text { OR } 2.6,95 \% \text { CI } 1.2-5.5 \text { for advanced fibrosis } \\
\text { BARD score: } 43 \% \text { PPV and } 96 \% \text { NPV for detecting fibrosis } \\
\text { stage 3-4 }\end{array}$ \\
\hline
\end{tabular}

Measuring liver stiffness is another noninvasive method of assessing fibrosis in this organ. However, obesity, particularly waist circumference, has been identified as the main impediment that leads to uninterpretable liver stiffness measurements (18). Owing to the limitations of the Transient elastography (FibroScan) $M$ probe, technological improvement in the form of a novel Transient elastography (FibroScan) XL probe led to better results. The XL probe could reliably be used with $100 \%$ success rate (19). Acoustic radiation force impulse (ARFI) shear wave imaging for liver stiffness could also be used to differentiate low from high fibrosis stages in individuals with obesity-related NAFLD (11).

Magnetic resonance is a non-invasive imaging surrogate for the assessment of hepatic steatosis. It can be used to both diagnose and histologically grade NAFLD. Proton magnetic resonance imaging (MRI) usually shows the two dominant peaks attributable to water and to methylene protons of fatty acids, from which the hepatic proton density that is attributable to fat can be calculated (20). An assessment of liver stiffness 
was performed by two-dimensional magnetic resonance elastography (2D MRI) to predict advanced liver fibrosis in a cross-sectional prospective analysis of 117 consecutive patients with biopsy-proven NAFLD (12). A novel 3D MRI was recently used to diagnose NASH and advanced fibrosis in NAFLD patients (13).

A higher AST-to-platelet ratio index (APRI) was associated with more advanced fibrosis in a sample of 111 biopsy-proven NAFLD patients (21). APRI was higher among obese individuals regardless of the presence of NAFLD, and among obese NAFLD compared to non-NAFLD subject. In this sample of adolescents, a higher APRI score could predict a higher cardiovascular risk profile (carotid intima-media thickness) (14).

The BARD score combines BMI, AST/ALT ratio and the presence of diabetes mellitus, based on the sum of BMI $(\geq 28=1)$, AST/ALT ratio $(\geq 0.8=$ 2 ) and diabetes mellitus (present $=1$ ). This score classifies NAFLD patients according to disease severity, particularly advanced fibrosis, and can be used in individuals with co-morbidities related to MS (15).

\section{Liver Enzymes}

Biochemical changes in the liver can be correlated with histological abnormalities and immune responses. Aminotransferase levels generally correlated with the degree of hepatic steatosis but not with the degree of hepatic fibrosis $(22,23)$. ALT levels are generally higher than AST levels in NAFLD patients. ALT may be elevated 2-4 times over the upper limit of normal, yet a large number of patients may present ALT levels within normal ranges $(24,25)$. Levels of liver enzymes in NAFLD patients are detailed in Table 2 (26-33).

AST and ALT levels were elevated in NAFLD patients compared to non-NAFLD patients in samples of obese children and adolescents. Elevated AST and ALT levels were also noted in patients with steatosis compared to those without steatosis (26-33). $\gamma$-GTP levels were also higher in NAFLD compared to non-NAFLD patients in a large sample (32), yet were comparable between NAFLD and non-NAFLD patients in a smaller sample of obese children (27). There were no differences in AST and ALT levels between nonNAFLD obese patients and lean controls (29). There were no differences in ALT levels between
NASH and non-NASH in a small sample of obese adolescents (34).

AST, ALT and $\gamma$-GTP levels decreased, particularly among NAFLD patients, following a 1 year intervention using interdisciplinary therapy (clinical, nutritional and psychological), exercise (60 $\mathrm{min} /$ day for 3 days/week) and physiotherapy in 79 obese adolescents (33). ALT (mean change -36 $\mathrm{U} / \mathrm{L}, \mathrm{p}<0.05$ ) and AST (mean change $-22 \mathrm{U} / \mathrm{L}$, $\mathrm{p}<0.05)$ levels decreased at the 1 year follow-up in a sample of 39 obese children enrolled in a multidisciplinary program of dietary and exercise advice with baseline elevated ALT (mean 110 U/L) and AST (mean $81 \mathrm{U} / \mathrm{L}$ ) (35).

Changes in AST, ALT and $\gamma$-GTP were also analysed in 58 postpubertal obese adolescents randomized to aerobic training (AT; 15 without NAFLD and 14 with NAFLD) or aerobic plus resistance training (AT + RT; 15 without NAFLD and 14 with NAFLD). Baseline AST, ALT and $\gamma$ GTP levels were elevated in the NAFLD group compared to the non-NAFLD group among patients randomized to AT. This form of exercise did not lead to significant changes in the non-NAFLD group at 1 year follow-up. AT led to significant decreases in AST $(-6.61 \pm 7.65 \mathrm{IU} / \mathrm{L}, \mathrm{p}<0.05)$ and ALT $(-21.84 \pm 23.76 \mathrm{IU} / \mathrm{L}, \mathrm{p}<0.05)$ compared to baseline in NAFLD patients, with non-significant decreases in $\gamma$-GTP. Likewise, AT + RT did not lead to significant changes in the non-NAFLD group at 1 year follow-up. In the AT + RT group, ALT was elevated in NAFLD vs. non-NAFLD. ALT was the only liver enzyme whose levels decreased significantly in NAFLD following 1 year of AT + RT (-5.78 $\pm 9.73 \mathrm{IU} / \mathrm{L}, \mathrm{p}<0.05)$ (36).

\section{Cytokine, Chemokine, Apoptosis Biomarkers}

Dysregulation of hepatic metabolism, as result of lipotoxicity signaling and inflammatory processes, illustrates the cytokines imbalance that leads to liver injury. Gut microbiota influences the arrival of lipopolysaccharide (LPS) to the portal vein. Inflammatory markers most frequently associated with NAFLD/NASH include tumor necrosis factor (TNF)- $\alpha$, interleukin (IL)-6 and IL-8, matrix metalloproteinases and high-sensitivity $\mathrm{C}$-reactive protein (hsCRP) (37). The relationship between NAFLD and inflammatory markers such as TNF- $\alpha$, IL-6 and hsCRP was recently reviewed by Neuman et al. (3). All 3 of these inflammatory markers were 
Table 2: Liver Enzymes in NAFLD Patients

\begin{tabular}{|c|c|}
\hline and Study Population & Levels of Biomarker \\
\hline $\begin{array}{l}26 \\
33 \text { overweight or obese children } \\
(15 \text { with NAFLD and } 18 \text { with } \\
\text { normal liver histology) }\end{array}$ & Mean ALT: $43 \pm 6$ in NAFLD vs. $28 \pm 7$ IU/L in \\
\hline $\begin{array}{l}27 \\
144 \text { obese child } \\
\text { steatosis and } 94 \text { wi }\end{array}$ & $\begin{array}{l}\text { Mean AST: } 25.71 \pm 6.59 \text { in steatosis vs. } 23.67 \pm 5.08 \text { IU/L in non-steatosis } \\
(\mathrm{p}=0.042) \\
\text { Mean ALT: } 28.10 \pm 18.78 \text { in steatosis vs. } 20.59 \pm 5.85 \text { IU/L in non- } \\
\text { steatosis }(\mathrm{p}=0.009)\end{array}$ \\
\hline $\begin{array}{l}28 \\
88 \text { obese chil } \\
\text { NAFLD and } 44 \mathrm{u}\end{array}$ & $\begin{array}{l}\text { Mean AST: } 34 \text { in NAFLD vs. } 24 \text { IU/L in non-NAFLD }(\mathrm{p}<0.01) \\
\text { Mean ALT: } 45 \text { in NAFLD vs. } 20 \text { IU/L in non-NAFLD }(\mathrm{p}<0.01)\end{array}$ \\
\hline $\begin{array}{l}\text { nts (45 with } \\
\text { out NAFLD) }\end{array}$ & $\begin{array}{l}\text { ese NAFLD, } 23.4 \pm 14.1 \text { in non-NAFLD } \\
\text { ean controls }(\mathrm{p}<0.05 \text { for both) } \\
\text { FLD, } 24.7 \pm 8.3 \text { in non-NAFLD obese and } \\
(\mathrm{p}<0.05 \text { for both) }\end{array}$ \\
\hline $\begin{array}{l}30 \\
217 \quad \text { obese children and } \\
\text { adolescents }(8-15 \text { years of age })\end{array}$ & $\begin{array}{l}\text { Mean AST: } 30.5 \pm 16.8 \text { in NAFLD vs. } 24.4 \pm 8.02 \text { IU/L in non-NAFLD } \\
(\mathrm{p}=0.002) \\
\text { Mean ALT: } 35.5 \pm 24.3 \text { in NAFLD vs. } 24.9 \pm 13.3 \mathrm{IU} / \mathrm{L} \text { in non-NAFLD } \\
(\mathrm{p}=0.001)\end{array}$ \\
\hline $\begin{array}{l}31 \\
120\end{array}$ & $\begin{array}{l}\text { Mean ALT: } 35.4 \pm 4.6 \text { in NAFLD vs. } 18.9 \pm 1.8 \text { IU/L in non-NAFLD } \\
(\mathrm{p}=0.005) \\
\begin{array}{l}\text { Mean AST: } 28.8 \pm 2.8 \text { in NAFLD vs. } 21.4 \pm 1.3 \text { IU/L in non-NAFLD } \\
(\mathrm{p}=0.035)\end{array}\end{array}$ \\
\hline $\begin{array}{l}\text { veight or obese children } \\
\text { NAFLD and } 337 \text { with } \\
\text { er histology) }\end{array}$ & $\begin{array}{l}\text { AST: } 26 \text { in NAFLD vs. } 19 \mathrm{IU} / \mathrm{L} \text { in non-NAFLD }(\mathrm{p}<0.001) \\
\text { ALT: } 37 \text { in NAFLD vs. } 20 \mathrm{IU} / \mathrm{L} \text { in non-NAFLD }(\mathrm{p}<0.001) \\
\text {-GTP: } 21 \text { in NAFLD vs. } 15 \mathrm{IU} / \mathrm{L} \text { in non-NAFLD }(\mathrm{p}<0.001)\end{array}$ \\
\hline $\begin{array}{l}33 \\
79 \text { obese adolescents ( } 33 \text { with } \\
\text { NAFLD and } 46 \text { without NAFLD) } \\
\text { Interdisciplinary (clinical, } \\
\text { nutritional and psychological) } \\
\text { therapy, exercise ( } 60 \mathrm{~min} / \text { day for } \\
3 \text { days/week) and physiotherapy } \\
\text { for } 1 \text { year }\end{array}$ & $\begin{array}{l}\text { Mean AST: } 23 \pm 4 \text { at baseline vs. } 22 \pm 11 \mathrm{IU} / \mathrm{L} \text { at follow-up in non- } \\
\text { NAFLD } \\
\text { Mean AST: } 25 \pm 7 \text { at baseline vs. } 22 \pm 7 \text { IU/L at follow-up in NAFLD } \\
\text { (p<0.05) } \\
\text { Mean ALT: } 22 \text { at baseline vs. } 16 \mathrm{IU} / \mathrm{L} \text { at follow-up in non-NAFLD } \\
\text { (p<0.05) } \\
\text { Mean ALT: } 27 \text { at baseline vs. } 21 \mathrm{IU} / \mathrm{L} \text { at follow-up in NAFLD (p<0.05) } \\
\text { Mean } \gamma \text {-GTP: } 22 \text { at baseline vs. } 18 \mathrm{IU} / \mathrm{L} \text { at follow-up in non-NAFLD } \\
(\mathrm{p}<0.05) \\
\text { Mean } \gamma \text {-GTP: } 24 \text { at baseline vs. } 18 \mathrm{IU} / \mathrm{L} \text { at follow-up in NAFLD }(\mathrm{p}<0.05)\end{array}$ \\
\hline
\end{tabular}

elevated in NAFLD patients compared to healthy controls. Higher TNF- $\alpha$ and hsCRP levels correlated with NASH compared to non-NASH in most NAFLD samples, but not in others. IL-6 levels were different between NAFLD and controls, but were not correlated with the degree of steatosis. HsCRP levels were further elevated in obese subjects compared to lean controls $(0.61 \pm 1.08$ in obese vs. $0.33 \pm 0.25$ in overweight vs. $0.05 \pm 0.18$ $\mathrm{mg} / \mathrm{dL}$ in controls), with no significant differences between obese and overweight subjects in terms of serum hsCRP levels $(3,28,38-40)$.

Cytokeratin (CK)-18, the major intermediate filament protein of the liver, is cleaved by caspases during hepatocyte apoptosis, leading to the formation of CK-18 fragments that can be detected 
by immunoassay (41). The M30 assay detects hepatocytes apoptosis, while the M65 (M6 capture and M5 detection antibodies) and M65ED (M5 capture and M6 detection antibodies) assays detect total cell death (3). Recent studies have found that both assays can distinguish individuals with fibrosis from healthy controls, but only M65 and M65ED can differentiate between the different stages on fibrosis in NAFLD patients (low or moderate vs. advanced fibrosis) $(42,43)$.

Hyaluronic acid is a non-invasive serum biomarker that can be used to assess liver fibrosis in NAFLD patients. Elevated serum HA levels primarily indicate advanced fibrosis and steatosis (44). Additionally, hyaluronic acid can be incorporated into the enhanced liver fibrosis score, comprising of amino-terminal propeptide of procollagen type III, tissue inhibitor of matrix metalloproteinase-1 and hyaluronic acid, which could further be used to predict fibrosis (41). Our group has recently reviewed in detail the use of hyaluronic acid as a biomarker for the diagnosis of liver fibrosis (45).

\section{Non-alcoholic Fatty Liver Disease and Iron}

A feature of NAFLD patients that differentiates them from patients with alcoholic liver disease is a different expression profile of iron-related proteins. Iron parameters in several NAFLD samples are described in Table 3 (46-49).

Serum ferritin levels were significantly higher in obese subjects compared to overweight subjects in a small sample of 64 pediatric NAFLD patients. Mean transferrin saturation and mean serum iron levels were comparable between the groups (48). Increased serum ferritin levels were found with higher incidence among individuals with more advanced fibrosis in a large sample of 1014 NAFLD patients confirmed by liver biopsy. However, no cut-off value for this biomarker could be established that would help predict fibrosis stage with satisfactory sensitivity and specificity (50). A statistically significant increase in serum ferritin with increasing histological grade of steatosis was also noted in a large Japanese sample of NAFLD patients. However, the predictive value of this noninvasive marker was once again found to be unsatisfactory (51).

Iron deficiency (transferrin saturation $<20 \%$ ) was observed in $34.2 \%$ of subjects included in a large sample of 675 NAFLD patients. It was observed predominantly among subjects with MS. Iron deficiency was correlated with lower serum hepcidin levels, a phenomenon believed to result from lower circulating iron levels (52). Obesity but not NAFLD were associated with elevated serum hepcidin levels in a large sample of patients undergoing bariatric surgery (49).

A recent study shows that no improvements in liver enzymes, hepatic fat or insulin resistance were achieved by reducing ferritin through phlebotomy in a sample of 74 NAFLD subjects (33 underwent phlebotomy and 41 were controls) (53). Removal of iron by phlebotomy reduced serum ferritin but had no influence on markers of inflammation. Beaton et al. (54) show that elevated serum ferritin is not related to inflammation in NAFLD. Reduction in serum ferritin led to reduction in aminotransferases (55).

Body iron levels were higher in individuals with suspected NAFLD, assessed by elevated ALT levels, in a large sample of 2186 adults. In this sample, hemoglobin levels were correlated with suspected NAFLD. No correlation between serum ferritin levels and suspected NAFLD was identified. Overall, this study identified a positive correlation between higher hemoglobin levels and elevated ALT, which could indicate the presence of NAFLD (56). Losekann et al. (57) found only low iron deposition in liver biopsies of NAFLD patients referred for bariatric surgery, suggesting that iron is unlikely to play a major role in the pathogenicity of NAFLD.

Serum bilirubin is negatively correlated with the presence of NASH on biopsy in children. Mean total bilirubin was lower in NASH compared to non-NASH $(0.65 \pm 0.24$ vs. $0.73 \pm 0.22 \mathrm{mg} / \mathrm{dL}$, $\mathrm{p}=0.007)$. The presence of steatosis on biopsy and the NAFLD activity score $(\mathrm{p}<0.05)$, and to a certain degree the presence of fibrosis and inflammation $(\mathrm{p}=0.051)$, were associated with lower odds of having high serum bilirubin levels (58).

\section{Association with Kidney Diseases}

NASH mediates other risk factors such as its comorbidity with kidney involvement in the presence or absence of MS. NAFLD was associated with higher odds of chronic kidney disease (CKD) in several recent studies, as described in Table 4 (5970). Compared to non-NAFLD, NAFLD was also 
Table 3: Markers of iron overload in non-alcoholic fatty liver disease patients

\begin{tabular}{|c|c|c|}
\hline Reference & Population & Biomarker Measured \\
\hline 46 & $\begin{array}{l}30 \text { controls } \\
50 \quad \text { non-NAFLD } \\
\text { obese } \\
30 \text { obese NAFLD }\end{array}$ & $\begin{array}{l}\text { Mean ALT: } 16 \pm 5.6 \text { in control, } 26.9 \pm 18.6 \text { in obese overall }(\mathrm{p}=0.002 \text { vs. } \\
\text { control), } 20.9 \pm 10.9 \text { in non-NAFLD obese and } 36.8 \pm 24 \mathrm{U} / \mathrm{L} \text { in obese } \\
\text { NAFLD }(\mathrm{p}<0.001 \text { vs. non-NAFLD obese) } \\
\text { Mean AST: } 21.4 \pm 5.4 \text { in control, } 22.9 \pm 9.1 \text { in obese overall, } 21.3 \pm 6.6 \text { in } \\
\text { non-NAFLD obese and } 25.4 \pm 11.9 \mathrm{U} / \mathrm{L} \text { in obese NAFLD ( } \mathrm{p}=0.053 \mathrm{vs} \text {. } \\
\text { non-NAFLD obese) } \\
\text { Mean iron: } 72 \pm 31.5 \text { in control, } 64.8 \pm 31.3 \text { in obese overall, } 64 \pm 33.4 \text { in } \\
\text { non-NAFLD obese and } 66 \pm 27.9 \mu \mathrm{g} / \mathrm{dL} \text { in obese NAFLD } \\
\text { Mean iron-binding capacity: } 388.3 \pm 65 \text { in control, } 385 \pm 61.3 \text { in obese } \\
\text { overall, } 401.3 \pm 58.8 \text { in non-NAFLD obese and } 357.9 \pm 56.5 \mu \mathrm{g} / \mathrm{dL} \text { in } \\
\text { obese NAFLD ( }=0.002 \text { vs. non-NAFLD obese) } \\
\text { Median ferritin: } 27.3 \text { in control, } 39.5 \text { in obese overall, } 36.3 \text { in non-NAFLD } \\
\text { obese and } 43.1 \text { in obese NAFLD } \\
\text { Mean transferrin saturation: } 18.8 \pm 8.4 \text { in control, } 17.4 \pm 9.3 \text { in obese } \\
\text { overall, } 16.4 \pm 9.3 \text { in non-NAFLD obese and } 19.1 \pm 9.1 \% \text { in obese NAFLD } \\
\text { Median hepcidin: } 474.5 \text { in control, } 473.6 \text { in obese overall, } 457.7 \text { in non- } \\
\text { NAFLD obese and } 714.3 \text { in obese NAFLD ( }<0.001 \text { vs. non-NAFLD } \\
\text { obese) }\end{array}$ \\
\hline 47 & $\begin{array}{l}15 \text { non-diabetic } \\
\text { NAFLD adults } \\
15 \quad \text { non-diabetic } \\
\text { matched controls }\end{array}$ & $\begin{array}{l}\text { Mean ferritin: } 206.7 \pm 182.0 \text { in control vs. } 361.8 \pm 532.5 \mathrm{pmol} / \mathrm{L} \text { in NAFLD } \\
(\mathrm{p}=0.001) \\
\text { Mean transferrin-iron saturation: } 23 \pm 2 \text { in control vs. } 30 \pm 3 \% \text { in NAFLD } \\
(\mathrm{p}=0.05)\end{array}$ \\
\hline 48 & $\begin{array}{l}16 \text { overweight } \\
\text { pediatric NAFLD } \\
\text { (control) } \\
48 \text { obese pediatric } \\
\text { NAFLD patients }\end{array}$ & $\begin{array}{l}\text { Mean transferein saturation: } 45.88 \pm 72.41 \text { in overweight vs. } 34.31 \pm \\
45.76 \% \text { in obese } \\
\text { Mean serum iron: } 98.25 \pm 19.60 \text { in overweight vs. } 97.10 \pm 39.16 \mu \mathrm{g} / \mathrm{dL} \text { in } \\
\text { obese } \\
\text { Mean ferritin: } 83.21 \pm 50.20 \text { in overweight vs. } 133.51 \pm 114.87 \mathrm{ng} / \mathrm{mg} \text { in } \\
\text { obese }(\mathrm{p}=0.03)\end{array}$ \\
\hline 49 & $\begin{array}{l}105 \text { patients } \\
\text { undergoing } \\
\text { bariatric surgery } \\
60 \text { healthy controls }\end{array}$ & $\begin{array}{l}\text { Mean serum hepcidin: } 19.1 \pm 11.0 \text { in patients vs. } 2.9 \pm 3.5 \mathrm{ng} / \mathrm{mL} \text { in } \\
\text { controls ( }<<0.001 \text { ) } \\
\text { Mean serum ferritin: } 50.4 \pm 48.8 \text { in patients vs. } 11.8 \pm 13.6 \mathrm{ng} / \mathrm{mL} \text { in } \\
\text { controls ( }<<0.001 \text { ) }\end{array}$ \\
\hline
\end{tabular}

associated with CKD in a large meta-analysis [pooled hazard ratio (HR) $2.12,95 \%$ confidence interval (CI) 1.69-2.66, $\mathrm{p}<0.00001$ from crosssectional studies and pooled HR $1.79,95 \%$ CI 1.65 $1.95, \mathrm{p}<0.00001$ from longitudinal studies] (71). This association generally remained significant after controlling for confounding variables such as gender, age, BMI, waist circumference, homeostatic model assessment-insulin resistance (HOMA-IR) index, blood pressure, smoking status, physical activity, diabetes duration, glycosylated hemoglobin, lipids, baseline estimated glomerular filtration rate (eGFR), AST, ALT, $\gamma$-GTP, hypertension, diabetes mellitus, hypertriglyceridemia, low high-density lipoprotein cholesterol, microalbuminuria and medications $(60,62,64,65,70,71)$.

NAFLD was further linked to lower eGFR, as well as a greater frequency of abnormal albuminuria (61). An association between NAFLD and a higher albumin-to-creatinine ratio was identified in another study (68). The presence of intermediate or high probability of liver fibrosis assessed by non-invasive markers could predict the presence of CKD in NAFLD patients (70). Decreased eGFR and increased albuminuria were associated with NASH severity in terms of steatosis and fibrosis $(61,67,71)$. The incidence of mild 
Table 4: Association between NAFLD and CKD

\begin{tabular}{l}
\hline Reference and Population \\
\hline 59 \\
2103 type 2 diabetes patients $(67.6 \%$ had NAFLD; \\
$13.5 \%$ had CKD) \\
60
\end{tabular}

1760 type 2 diabetes patients with normal or nearAssociation

NAFLD associated with CKD (OR 1.87, 95\% CI 1.3-4.1, p=0.020) normal baseline kidney function (31.1\% developed CKD by the end of 6.5 years follow-up)

61

80 overweight patients with biopsy-proven NASH

80 nonsteatotic controls

\section{2}

1412 subjects $(39.0 \%$ had mild kidney function damage)

63

11469 individuals who had undergone liver ultrasonography (25.4\% had CKD defined as eGFR $\leq 60 \mathrm{ml} / \mathrm{min} / 1.73 \mathrm{~m}^{2}$ or the presence of albuminuria in subjects with an eGFR $>60 \mathrm{ml} / \mathrm{min} / 1.73 \mathrm{~m}^{2}$ )

64

343 patients with type 1 diabetes $(53.1 \%$ had

NAFLD diagnosed by ultrasonography)

65

1706 subjects who underwent routine health examination $31.9 \%$ had NAFLD and $24.9 \%$ had $\mathrm{CKD}$, defined as either proteinuria or glomerular filtration rate $\leq 60 \mathrm{~mL} / \mathrm{min}$ per $1.73 \mathrm{~m}^{2}$ )

66

747 patients with normal or near normal liver and kidney functions (35.8\% had NAFLD)

67

62 CKD patients $(46.8 \%$ with stage III CKD and $53.2 \%$ with stage IV CKD; $85.5 \%$ had NAFLD)

68

190 pre-diabetic or diabetic patients $(66.8 \%$ had NAFLD)

CKD defined as estimated GFR $<60 \mathrm{~mL} / \mathrm{min} / 1.73$

$\mathrm{m}^{2}$ and/or albumin-to-creatinine ratio $\geq 30 \mathrm{mg} / \mathrm{g}$

69

148 morbidly obese patients with biopsy-proven NAFLD (37 with NASH and 111 with steatosis)

70

570 patients with ultrasonography-diagnosed

NAFLD $(48.9 \%$ had intermediate and $9.6 \%$ had

high probability of fibrosis; $6.7 \%$ had CKD defined as eGFR $<60 \mathrm{~mL} / \mathrm{min} / 1.73 \mathrm{~m}^{2}$ )
NAFLD associated with CKD (OR 1.69, 95\% CI 1.3-2.6, p<0.001)

NASH associated with CKD (25.0\% in NASH vs. $3.7 \%$ in control)

NASH associated with lower eGFR $(75.3 \pm 12$ in NASH vs. $87.5 \pm$ $6 \mathrm{~mL} / \mathrm{min} / 1.73 \mathrm{~m}^{2}$ in control)

NASH associated with abnormal albuminuria (14.0\% in NASH vs. $2.5 \%$ in control)

Severe NAFLD associate with a higher incidence of mild kidney function damage compared to mild NAFLD (OR 1.91 vs. OR 1.44, $\mathrm{p}=0.015$ )

NAFLD associated with CKD (OR 1.47, 95\% CI 1.29-1.67, $\mathrm{p}<0.0001)$

Incidence of NAFLD higher among CKD patients than among patients without CKD $(42.2 \%$ vs. $34.5 \%, \mathrm{p}<0.0001)$

NAFLD associated with decreased eGFR $(83.0 \pm 27$ vs. $93.3 \pm 29$ $\mathrm{mL} / \mathrm{min} / 1.73 \mathrm{~m}^{2}, \mathrm{p}<0.0001$ )

NAFLD associated with abnormal albuminuria (50.0 vs. $20.5 \%$, $\mathrm{p}<0.0001)$

NAFLD associated with CKD (54.4 vs. $24.2 \%$, p $<0.0001)$

NAFLD associated with CKD (OR 1.69, 95\% CI 1.34-2.12)

NAFLD associate with renal impairment such as higher incidences of microalbuminuria $(\mathrm{p}<0.001)$ and macroalbuminuria $(\mathrm{p}<0.001)$

Severity of steatosis correlated positively with serum creatinine $(\mathrm{p}<0.01)$ and with CRP levels $(\mathrm{p}<0.05)$

Severity of steatosis correlated negatively with eGFR $(p<0.01)$ and serum iron concentration $(\mathrm{p}<0.01)$

NAFLD associated with CKD compared to non-NAFLD (32.3 vs $17.5 \%, \mathrm{p}=0.03$ )

NAFLD associated with elevated serum uric acid level compared to non-NAFLD $(391.86 \pm 97.07$ vs. $347.92 \pm 106.42 \mu \mathrm{mol} / \mathrm{L}$, $\mathrm{p}=0.005)$

NAFLD not associated with eGFR $(\mathrm{p}=0.67)$

NASH associated with eGFR $<90 \mathrm{~mL} / \mathrm{min} / 1.73 \mathrm{~m}^{2}$ (OR 3.0, 95\% CI 1.3-7.0) or with eGFR $<60 \mathrm{~mL} / \mathrm{min} / 1.73 \mathrm{~m}^{2}$ (OR 9.7, 95\% CI 1.0-96.4)

Intermediate and high probability of fibrosis associated with lower eGFR $(p<0.0001)$

CKD more common in NAFLD with high (OR 5.13, 95\% CI 1.1323.28, $\mathrm{p}=0.03$ ) and intermediate (OR 3.01, 95\%CI 0.87-10.32, $\mathrm{p}=0.07$ ) probability of fibrosis compared to low probability of liver fibrosis 
kidney function damage was higher in patients with more severe NAFLD (62). A decreased eGFR was further associated with lobular inflammation and severe fibrosis, suggesting a common inflammatory pathway associated with both renal and hepatic lesions in NAFLD patients (69).

The association between MS and the cooccurrence of NAFLD and CKD remains controversial. NAFLD usually remains associated with CKD after controlling for components of MS in most studies. It is likely that the two conditions share common pathogenic mechanisms like obesity, abdominal obesity, insulin resistance, hyperlipidemia, hypertension and inflammation $(60,62,64,65,70-72)$. The main causes of CKD in NAFLD patients are hypertensive and diabetic nephropathy, and these appear to be mediated by risk factors associated to MS, suggesting that MS may be a common risk factor for both conditions (73).

However, this association was lost upon adjusting for demographics and components of MS in another study (63). Alternatively, as these conditions can co-occur in the absence of obesity or other features of MS, a common inflammatory pathway may be responsible for both liver and kidney damage (72). Another explanation is that NAFLD may contribute to worsening of glycemic control in type 2 diabetes patients, in turn causing the development or progression of complications of diabetes such as cardiovascular disease and CKD (74). NAFLD was associated with CKD in nondiabetic populations as well, further suggesting that the two conditions may share a common pathological pathway (62). Going on the premise that NAFLD and CKD share common risk factors, each can simply be a marker of the other rather than considering NAFLD a risk factor for CKD (75).

The clinical aspects of NASH, as part of MS, can be monitored by non-invasive biomarkers. Markers of NAFLD such as ALT, $\gamma$-GTP and bilirubin were elevated among individuals with higher serum creatinine levels in a sample of 313 normo-albuminuric type 1 diabetic patients with eGFR $>60 \mathrm{~mL} / \mathrm{min} / 1.73 \mathrm{~m}^{2}$, while alkaline phosphatase levels were higher in subjects with elevated urinary albumin excretion rate (76). Serum acid uric levels were associated with NAFLD and MS in patients with normal kidney function in a cross-sectional study performed on 1141 middleaged and elderly participants. This association was absent among individuals with eGFR $<90$ $\mathrm{ml} / \mathrm{min} / 1.73 \mathrm{~m}^{2}$ (77).

Progression of CKD was assessed in 455 adult liver transplant recipients. Pre-liver transplant eGFR $<60 \mathrm{~mL} / \mathrm{min} / 1.73 \mathrm{~m}^{2}$ (OR 3.28, 95\% CI 1.76$6.10, \mathrm{p} \leq 0.001$ ), female gender (OR 2.96, 95\% CI $1.72-5.10, \mathrm{p}<0.001)$ and age (OR $1.09,95 \% \mathrm{CI}$ $1.05-1.12, \mathrm{p}<0.001)$ predicted stage $\geq 3 \mathrm{CKD}$ at 1 year post-liver transplant. Female gender (OR 2.52, 95\% CI 1.25-4.71, $\mathrm{p}=0.004)$, age (OR $1.05,95 \%$ CI 1.02-1.08, p=0.003) and NASH (OR 2.95, 95\% CI 1.06-8.21, $\mathrm{p}=0.039)$ predicted stage $\geq 3 \mathrm{CKD}$ at 5 years post-liver transplant, while a pre-liver transplant diagnosis of diabetes was associated with stage $4 \mathrm{CKD}$ at 5 years post-liver transplant (OR 2.91, 95\% CI 1.33-6.36, p=0.008) (78).

Liver graft, kidney graft, and patient survival at 5 years after transplantation were $72 \%, 72 \%$ and $74 \%$, respectively, in a sample of $221 \mathrm{NASH}$ patients who received simultaneous liver and kidney transplantation (incidence of diabetes was $71 \%$ and mean creatinine level was $3.6 \pm 1.9$ $\mathrm{mg} / \mathrm{dL}$ ) (79). The presence of NAFLD in renal transplant recipients is associated with an increased cardiovascular risk with respect to carotid atherosclerosis development (80).

The presence of NAFLD diagnosed by transient elastography was observed in $57.5 \%$ of a sample of 73 renal transplant recipients with a functioning graft after $>1$ year. The severity of liver steatosis correlated positively with serum creatinine levels and negatively with eGFR. The authors recommend the use of non-invasive screening methods to detect NAFLD in renal transplant recipients in order to prevent graft dysfunction (81).

\section{Non-alcoholic Fatty Liver and Alcohol Consumption}

Since alcoholic liver disease and NAFLD have a similar spectrum of progression, it has been thought intuitively likely that alcohol will have a deleterious effect on the progression of NAFLD and that its consumption should be discouraged. This assumption is not, however, supported by evidencebased medicine.

It appears that the histological effect of modest alcohol consumption is that of a decrease in the prevalence of steatohepatitis. Dunn et al. (82) recently published their analysis of data from 2 large population-based trials. One was the large 
NAFLD Database (83) and the other was the PIVENS trial of pioglitazone and vitamin E (84). There were 251 lifetime non-drinkers in these studies and they were compared to 331 modest drinkers. The exclusion criteria included drinking $>20 \mathrm{~g} /$ day, $>2$ drinks in a typical drinking day, or binge drinking at least once a month. These data are presented in Table 5 (82). From these data, it can be seen that modest drinking resulted in a significant improvement in the histological severity of the NAFLD. On multivariate analysis after adjusting for age, gender, ethnicity, income, education, body mass index, physical activity, smoking and diet, the OR for steatohepatitis was 0.52. A study from Australia of 105 consecutive patients undergoing bariatric surgery $(24.8 \%$ had NASH), found that moderate alcohol consumption resulted in an OR of 0.35 for NASH and an OR of 0.18 for diabetes mellitus (85).

It appears that not all alcoholic beverages have the same effect. A review of the NHANES III data compared 7211 non-drinkers and 945 individuals who consumed a modest amount of wine of up to $10 \mathrm{~g} / \mathrm{day}$. The presence of NAFLD was assumed if there was an unexplained elevation of ALT above the upper limit of normal of the reference laboratory $(>43 \mathrm{U} / \mathrm{L})$ or established values for healthy subjects $(>30 \mathrm{U} / \mathrm{L}$ for men and $19 \mathrm{U} / \mathrm{L}$ for women). The OR for NAFLD was 0.16 for those with a diagnosis based on the reference laboratory values and 0.51 for those based on the healthy individuals' values. This was only significant for wine consumption and not for liquors or mixed drink consumption. As such, the protective effect of alcoholic beverages is only found for drinking red wine and not beer or liquor (86). This suggests that there may be an effect of a non-alcoholic component of wine. A study from the
University of Michigan's Hepatology clinic of patients with NAFLD and consumption of $<40$ g/week identified 77 patients with fatty liver on biopsy and 52 who had regular alcohol consumption. The median lifetime alcohol intake was 24 gram-years. On multivariate analysis, the OR for developing severe fibrosis (stage F3-4) for those with more than 24 gram-years of alcohol was 0.26 (87). A meta-analysis of seven studies has shown a reduced prevalence of the MS in men drinking $40 \mathrm{~g}$ of alcohol and women drinking 20 grams per day (88). A Japanese study found a protective effect of alcohol on fatty liver but not on the MS (89).

NAFLD also has extra-hepatic effects on the patient. It is important to remember that the aim of medical treatment is to increase, where possible, the quantity and quality of life years. This is best assessed by examining robust clinical end-points. Excess alcohol consumption can result in alcoholic cardiomyopathy (90). However, light to moderate alcohol consumption may protect against developing congestive heart failure. Data from the Framingham heart study showed that the OR for congestive heart failure was 0.42 among men who drank 8-14 drinks per week (91). Recently, a large European database has reported similar findings (92). Thus, low to moderate levels of alcohol intake are associated with reduced cardiovascular risk and ischemic strokes (93). Moderate alcohol consumption is also linked to a decrease overall mortality. The Cancer Prevention Study II of nearly 1.2 million US adults had data concerning alcohol consumption on 490,000 adults. The overall death rates and the cardiovascular disease death rate were all at their lowest in those adults who reported one drink daily (94).

Table 5: Prevalence of histological features in lifetime non-drinkers and modest drinkers (82)

\begin{tabular}{lcccc}
\hline $\begin{array}{l}\text { Pathological } \\
\text { manifestation }\end{array}$ & Non-drinker (\%) & Modest drinker (\%) & OR & p value \\
\hline Steatohepatitis & 69.8 & 53.2 & 0.52 & 0.0006 \\
\hline Fibrosis stage 3 & 20.3 & 14.7 & 0.56 & 0.0005 \\
\hline Fibrosis Stage 4 & 12.7 & 6.1 & & \\
\hline Ballooning degeneration & 48 & 36 & 0.62 & 0.006 \\
\hline Mallory-Denk bodies & 34.9 & 25.1 & 0.65 & 0.04
\end{tabular}


The ultimate study of a prospective trial in adults administered differing doses of alcohol and being followed for up to 20 years with regular liver biopsies will never be performed. Thus, we need to make recommendations based on the available evidence. On the basis of the data reviewed above it seems likely that mild to moderate alcohol consumption results in overall reduction in cardiovascular mortality, as well as a less severe histological picture in the liver.

While the study by Dunn et al. (82) regarding the decreased prevalence of steatohepatitis among modest alcohol drinkers appears initially convincing, there are some methodical limitations. Three major confounding factors are not included in the analysis. Diabetes mellitus was found to be present in $35 \%$ of the non-drinkers and $22 \%$ of the modest drinkers. This difference was highly significant $(p<0.001)$. Secondly, there was no mention made of the consumption of soft drinks which may contain fructose. NAFLD exhibits a spectrum of disease that progresses from simple steatosis to steatohepatitis and cirrhosis, with complications including end-stage liver disease and HCC $(95,96)$. Fructose consumption is known to be a significant risk factor for developing NAFLD (97). Thirdly, genetic factors may be involved, including the patatin-like phospholipase domaincontaining protein 3 (PNPLA3) polymorphisms $(82,98)$. There were no data available regarding the PNPLA3 1148M SNP that is linked to the development of NAFLD. The age of onset of at-risk alcohol consumption and the presence of the $1148 \mathrm{M}$ genetic variant are independently associated with cirrhosis (99). Other confounding factors exist in studies of possible hepatic benefits of light to moderate drinking. These are cross-sectional studies employing surrogate end-points. The estimate of the amount of alcohol consumed is based on selfreporting and it is possible that non-drinkers of alcohol may have stopped for other health-related issues.
Approximately $50 \%$ of the US adult population consume a modest amount of alcohol on a regular basis (100). The question of what is a safe level of alcohol consumption is debatable. The amounts advised are inconsistent and range from $<10 \mathrm{~g}$ (1 drink) to $<40 \mathrm{~g} / \mathrm{day}$. The timing and duration of consumption are not defined. The threshold for safe alcohol consumption as recommended in international guidelines is provided by the National Institute of Alcohol and Alcohol Abuse (NIAAA) (101). The data available regarding the effect of light to moderate alcohol consumption in NAFLD is confusing enough to have led to several International Liver associations including the American Association for the Study of Liver Diseases (AASLD) to conclude that "no recommendation can be made with regards to nonheavy consumption of alcohol by individuals with NAFLD" (1). The threshold for alcohol consumption to rule out ALD is shown in Table 6 $(1,102,103)$.

The NHANES survey of 13580 subjects in the 1988-1994 survey found that the prevalence of abnormal aminotransferases was elevated in those who consumed $>2$ drinks/day or in those who were overweight (body mass index $25-30 \mathrm{~kg} / \mathrm{m}^{2}$ ) or obese (body mass index $\geq 30 \mathrm{~kg} / \mathrm{m}^{2}$ ) (104). Those patients who were obese and had $>1$ drink/day had an increased risk for NAFLD. Also, binge drinking was associated with an increased risk of elevated aminotransferases among obese consumers of 1-2 drinks/day.

However, a different point of view may be that alcohol, which causes a similar histological pattern in the liver to NAFLD, can exacerbate the tissue damage related to NAFLD. The deleterious effect of alcohol on liver disease has been clearly shown in chronic HCV patients. HCV progresses at an increased rate in those patients who imbibe a high level of alcohol and even small doses have been linked to liver fibrogenesis (105). There is no safe limit for alcohol consumption in patients with

Table 6: Threshold for alcohol consumption to rule out alcoholic liver disease

\begin{tabular}{llll}
\hline Association & AASLD 2012 (1) & EASL 2010 (102) & APWP 2007 (103) \\
\hline Male & $210 \mathrm{~g} /$ week & $30 \mathrm{~g} / \mathrm{day}$ & $140 \mathrm{~g} / \mathrm{week}$ \\
\hline Female & $140 \mathrm{~g} /$ week & $20 \mathrm{~g} / \mathrm{day}$ & $70 \mathrm{~g} /$ week \\
\hline
\end{tabular}

AASLD - American Association for the Study of Liver Disease; APWP -Asia - Pacific Working Party for Non-Alcoholic Steatohepatitis; EASLD - European Association for the Study of the Liver 
$\mathrm{HCV}$. It does appear, however, that there is a deleterious effect of alcohol on both NASH and $\mathrm{HCV}$ cirrhosis. A study from the Cleveland Clinic of 315 patients with $\mathrm{HCV}$ cirrhosis and $195 \mathrm{NASH}$ cirrhotics examined the effect of alcohol consumption on the development of HCC (106). NASH was defined on the basis of cryptogenic cirrhosis and the presence of the MS without significant alcohol consumption. The median follow up was 3.2 years. HCC developed in $12.8 \%$ of cirrhotic NASH and $20.3 \%$ of cirrhotic HCV patients. For those patients with NASH cirrhosis, both older age and alcohol consumption were independently associated with HCC with a hazard ratio (HR) of 3.6.

\section{Behaviour: Depression and Anxiety}

Depression and anxiety are believed to induce inflammatory states which can lead to NAFLD progression (107). No differences were found between small groups of NAFLD patients and viral hepatitis patients with respect to the presence of depression or anxiety. Depression and anxiety, as assessed by questionnaires, were more predominant among females than among males in NAFLD patients. Depression or anxiety was not associated with liver transaminase levels or biochemical tests (107).

NAFLD was associated with one of the highest incidences of depression among patients with chronic liver disease among 184 NAFLD patients $(27.2 \%)$. Hypertension, smoking, history of lung disease, female gender and non-AfricanAmerican ethnicity were independent predictors of depression among NAFLD patients (108). Using elevated ALT as a surrogate marker of NAFLD, Zelber-Sagi et al. (109) show that elevated ALT was a significant independent predictor for the occurrence of minor (OR 2.02, 95\% CI 1.40-2.92) and major (OR 3.13, 95\% CI 1.81-5.40) depression in a prospective cohort study investigating 12180 adults referred for health examinations. This study suggests that the presence of NAFLD may lead to the development of depression (109). Depression was not associated with NAFLD in a large population-based study (110).

Anxiety (Multidimensional Anxiety Scale for Children scale) and depression (Children's Depression Inventory scale) were higher in 57 children with NAFLD compared to 39 age-matched control children. NAFLD children were found to suffer from emotional and behavioural problems more frequently than controls. In turn, this was associated with lower World Health Organization Quality of Life-BREF questionnaire scores for their mothers (111).

In turn, depression and anxiety appear to be risk factors for obesity. Depression was associated with higher weight after 6 months of follow-up in 48 overweight/obese NAFLD patients (112). There were no differences in terms of Pediatric Quality of Life Inventory between 48 children with NAFLD and 40 obese control children. However, NAFLD was associated with higher Children's Depression Inventory scores than obesity, suggesting depression to be more prevalent among NAFLD children compared to obese children (113). The prevalence and severity of obesity was analyzed in 144 patients with major depressive disorder and 141 healthy controls. More severe major depressive disorder was noted among patients with higher BMI (114).

Youssef et al. (115) examined the association between depression, anxiety and antidepressant pharmacotherapy, and the severity of histological features of NAFLD in 567 patients with biopsyproven NAFLD (53.4\% had subclinical depression and $14.1 \%$ had clinical depression; $45.3 \%$ had subclinical anxiety and $25.2 \%$ had clinical anxiety). Depression categories were associated with portal fibrosis grades $(\mathrm{p}=0.038)$, with a trend towards hepatocyte ballooning grades $(\mathrm{p}=0.085)$. Anxiety was associated with trends towards lobular inflammation grades $(\mathrm{p}=0.094)$ and portal fibrosis grades $(\mathrm{p}=0.063)$. Steatosis was associated with depression categories $(\mathrm{p}=0.043)$, with a borderline interaction with anxiety $(\mathrm{p}=0.055)(115)$.

The link between the gut - liver and brain is consistent with high endotoxinemia in NAFLD. The gut microbiota, in addition to endotoxin, produces urease, which transforms urea into ammonia and carbon dioxide. Patients with NAFLD are unable to process ammonia in the liver, which results in an increase in the systemic levels of ammonia, leading to neurotoxicity (116).

\section{CONCLUSIONS}

Liver injury in NAFLD/NASH is a multi-factorial phenomenon. The diverse aspects include the nature of the agents that produced the injury, the 
characteristics of the injury, the mechanism for the hepatotoxic effects, the circumstances and risk factors, and the medical and social importance. Some of the multiple factors involved in the pathogenesis of this chronic liver condition, ranging from steatosis to inflammation, are due to a multitude of mechanisms, including aberrant lipid metabolism. In addition, fatty liver infiltrations can occur from an imbalance between lipid influx, its synthesis and its turnover. Also, a diverse array of drugs of use and misuse can cause the full histological picture of the disease. The spectrum of NAFLD can also be seen in some genetic diseases.

\section{REFERENCES}

1. Chalasani N, Younossi Z, Lavine JE et al. The diagnosis and management of non-alcoholic fatty liver disease: Practice Guideline by the American Association for the Study of Liver Diseases, American College of Gastroenterology, and the American Gastroenterological Association. Hepatology 2012;55:2005-23.

2. Tannapfel A, Denk H, Dienes HP et al. Histopathological diagnosis of non-alcoholic and alcoholic fatty liver disease. Virchows Arch 2011;458:511-23.

3. Neuman MG, Cohen LB, Nanau RM. Biomarkers in nonalcoholic fatty liver disease. Can J Gastroenterol Hepatol 2014;28:607-18.

4. Neuman M, Hilzenrat $\mathrm{N}$, Cohen L, Winkler RE, Nanau R. Multiple factors involved in nonalcoholic hepatitis pathogenesis. Int $\mathrm{J}$ Hepatol 2012;2012:429805.

5. Adler M, Schaffner F. Fatty liver hepatitis and cirrhosis in obese patients. Am J Med 1979;67:8116.

6. Ludwig J, Viggiano TR, McGill DB, Ott BJ. Nonalcoholic steatohepatitis: Mayo Clinic experience with a hitherto unnamed disease. Mayo Clin Proc 1980;55:434-8.

7. Zimmerman HJ. Hepatotoxicity: Adverse Effects of Drugs and Other Chemicals on the Liver. 2nd Ed. Philadelphia: Lippinott- Williams-Wilkins, 1999.

8. Zimmerman HJ, Ishak KG. Non-alcoholic steatohepatitis and other forms of pseudoalcoholic liver disease. In: Hall P (Ed). Alcoholic Liver Disease Pathology and Pathogenesis. 2nd Ed. London: Edwarde Arnold, 1995, 165-198.

9. Angulo P, Hui JM, Marchesini G et al. The NAFLD fibrosis score: a noninvasive system that identifies liver fibrosis in patients with NAFLD. Hepatology 2007;45:846-54.

10. Poynard T, Ratziu V, Charlotte F et al. Diagnostic value of biochemical markers (NashTest) for the prediction of non alcoholo steato hepatitis in patients with non-alcoholic fatty liver disease. BMC Gastroenterol 2006;6:34.

11. Palmeri ML, Wang $\mathrm{MH}$, Rouze $\mathrm{NC}$ et al. Noninvasive evaluation of hepatic fibrosis using acoustic radiation force-based shear stiffness in patients with nonalcoholic fatty liver disease. J Hepatol 2011;55:666-72.

12. Loomba R, Wolfson T, Ang B et al. Magnetic resonance elastography predicts advanced fibrosis in patients with nonalcoholic fatty liver disease: A prospective study. Hepatology 2014;60:1920-8.

13. Loomba R, Wolfsen $T$, Haufe $W$ et al. Novel 3dimensional magnetic resonance elastography accurately diagnoses nonalcoholic steatohepatitis and advanced fibrosis in patients with biopsy-proven nonalcoholic fatty liver disease: A prospective cohort study. J Hepatol 2014;60:S33.

14. Sert A, Pirgon O, Aypar E, Yilmaz H, Dündar B. Relationship between aspartate aminotransferase-toplatelet ratio index and carotid intima-media thickness in obese adolescents with non-alcoholic fatty liver disease. J Clin Res Pediatr Endocrinol 2013;5:182-8.

15. Harrison SA, Oliver D, Arnold HL, Gogia S, Neuschwander-Tetri BA. Development and validation of a simple NAFLD clinical scoring system for identifying patients without advanced disease. Gut 2008;57:1441-7.

16. Vallet-Pichard A, Mallet V, Nalpas B et al. FIB-4: an inexpensive and accurate marker of fibrosis in $\mathrm{HCV}$ infection. comparison with liver biopsy and fibrotest. Hepatology 2007;46:32-6.

17. Poynard T, Munteanu M, Deckmyn $\mathrm{O}$ et al. Validation of liver fibrosis biomarker (FibroTest) for assessing liver fibrosis progression: proof of concept and first application in a large population. J Hepatol 2012;57:541-8.

18. Castéra L, Foucher J, Bernard PH et al. Pitfalls of liver stiffness measurement: a 5-year prospective study of 13,369 examinations. Hepatology 2010;51:828-35.

19. Myers RP, Pomier-Layrargues G, Kirsch R et al. Feasibility and diagnostic performance of the FibroScan XL probe for liver stiffness measurement in overweight and obese patients. Hepatology 2012;55:199-208.

20. Ligabue G, Besutti G, Scaglioni R, Stentarelli C, Guaraldi G. MR quantitative biomarkers of nonalcoholic fatty liver disease: technical evolutions and future trends. Quant Imaging Med Surg 2013;3:1925.

21. Kruger FC, Daniels CR, Kidd M et al. APRI: a simple bedside marker for advanced fibrosis that can avoid liver biopsy in patients with NAFLD/NASH. 
S Afr Med J 2011;101:477-80.

22. Mathiesen UL, Frazen LE Fryden A, Foberg U, Bodemar G. The clinaical significance of slightly to moderately increases liver transaminase values in asymptomatic patients. Scand J Gastroenterol 1999;34:85-91.

23. Adams LA, Sanderson S, Lindor KD, Angulo P. The histological course of nonalcoholic fatty liver disease: a longitudinal study of 103 patients with sequential liver biopsies. J Hepatol 2005;42:132-8.

24. Mofrad P, Contos MJ, Haque M et al. Clinical and histologic spectrum of nonalcoholic fatty liver disease associated with normal ALT values. Hepatology 2003;37:1286-92.

25. Fracanzani AL, Valenti L, Bugianesi E et al. Risk of severe liver disease in nonalcoholic fatty liver disease with normal aminotransferase levels: a role forinsulin resistance and diabetes. Hepatology 2008;48:792-8.

26. El-Koofy NM, Anwar GM, El-Raziky MS et al. The association of metabolic syndrome, insulin resistance and non-alcoholic fatty liver disease in overweight/obese children. Saudi J Gastroenterol 2012;18:44-9.

27. Navarro-Jarabo JM, Ubiña-Aznar E, Tapia-Ceballos $\mathrm{L}$ et al. Hepatic steatosis and severity-related factors in obese children. J Gastroenterol Hepatol 2013;28:1532-8.

28. Pacifico L, Bezzi M, Lombardo CV et al. Adipokines and $\mathrm{C}$-reactive protein in relation to bone mineralization in pediatric nonalcoholic fatty liver disease. World J Gastroenterol 2013;19:400714.

29. Pirgon O, Cekmez F, Bilgin H, Eren E, Dundar B. Low 25-hydroxyvitamin D level is associated with insulin sensitivity in obese adolescents with nonalcoholic fatty liver disease. Obes Res Clin Pract 2013;7:e275-83.

30. Atabek ME, Selver Eklioglu B, Akyürek N. Which metabolic syndrome criteria best predict nonalcoholic fatty liver disease in children? Eat Weight Disord 2014;19:495-501.

31. Lee S, Rivera-Vega M, Alsayed HM, Boesch C, Libman I. Metabolic inflexibility and insulin resistance in obese adolescents with non-alcoholic fatty liver disease. Pediatr Diabetes 2015;16:211-8.

32. Bedogni G, Gastaldelli A, Manco $M$ et al. Relationship between fatty liver and glucose metabolism: a cross-sectional study in 571 obese children. Nutr Metab Cardiovasc Dis 2012;22:120-6.

33. Sanches PL, de Piano A, Campos RM et al. Association of nonalcoholic fatty liver disease with cardiovascular risk factors in obese adolescents: the role of interdisciplinary therapy. J Clin Lipidol 2014;8:265-72.

34. Corey KE, Stanley TL, Misdraji J et al. Prevalence and outcome of non-alcoholic fatty liver disease in adolescents and young adults undergoing weight loss surgery. Pediatr Obes 2014;9:e91-3.

35. DeVore S, Kohli R, Lake $\mathrm{K}$ et al. A multidisciplinary clinical program is effective in stabilizing BMI and reducing transaminase levels in pediatric patients with NAFLD. J Pediatr Gastroenterol Nutr 2013;57:119-23.

36. de Piano A, de Mello MT, Sanches P de L et al. Long-term effects of aerobic plus resistance training on the adipokines and neuropeptides in nonalcoholic fatty liver disease obese adolescents. Eur J Gastroenterol Hepatol 2012;24:1313-24.

37. Neuman MG. Cytokines and chemokines in liver disease. In: al-Mahtab M, Rahman S (Eds). Liver, a complete book on Hepato-Pancreato-Biliary Diseases. India: Elsevier Reed India Ltd, 2009, 1924.

38. Armutcu F, Akyol S, Ucar F, Erdogan S, Akyol O. Markers in nonalcoholic steatohepatitis. Adv Clin Chem 2013;61:67-125.

39. Kitsios K, Papadopoulou M, Kosta K, Kadoglou N, Papagianni M, Tsiroukidou K. High-sensitivity Creactive protein levels and metabolic disorders in obese and overweight children and adolescents. J Clin Res Pediatr Endocrinol 2013;5:44-9.

40. Kwok R, Tse YK, Wong GL et al. Systematic review with meta-analysis: non-invasive assessment of non-alcoholic fatty liver disease-the role of transient elastography and plasma cytokeratin-18 fragments. Aliment Pharmacol Ther 2014;39:25469.

41. Alkhouri N, Carter-Kent C, Lopez R et al. A combination of the pediatric NAFLD fibrosis index and enhanced liver fibrosistest identifies children with fibrosis. Clin Gastroenterol Hepatol 2011;9:150-5.

42. Joka D, Wahl K, Moeller S et al. Prospective biopsy-controlled evaluation of cell death biomarkers for prediction of liver fibrosis and nonalcoholic steatohepatitis. Hepatology 2012;55:455-64.

43. Shen J, Chan HL, Wong GL et al. Assessment of non-alcoholic fatty liver disease using serum total cell death and apoptosis markers. Aliment Pharmacol Ther 2012;36:1057-66.

44. Toyoda H, Kumada T, Kiriyama $\mathrm{S}$ et al. Higher hepatic gene expression and serum levels of matrix metalloproteinase-2 are associated with steatohepatitis in non-alcoholic fatty liver diseases. Biomarkers 2013;18:82-7.

45. Neuman MG, Cohen LB, Nanau RM. Hyaluronic Acid as a Non-invasive Biomarker of Liver Fibrosis. Clin Biochem. 2015. pii: S0009-9120(15)00280-5. doi: 10.1016/j.clinbiochem.2015.07.019.

46. Demircioğlu F, Görünmez G, Dağıstan E et al. 
Serum hepcidin levels and iron metabolism in obese children with and without fatty liver: case-control study. Eur J Pediatr 2014;173:947-51.

47. Utzschneider KM, Largajolli A, Bertoldo A, et al. Serum ferritin is associated with non-alcoholic fatty liver disease and decreased B-cell function in nondiabetic men and women. J Diabetes Complications 2014;28:177-84.

48. Na JH, Park SW, Kang Y, Koh H, Kim S. The clinical significance of serum ferritin in pediatric non-alcoholic Fatty liver disease. Pediatr Gastroenterol Hepatol Nutr 2014;17:248-56.

49. Vuppalanchi R, Troutt JS, Konrad RJ, et al. Serum hepcidin levels are associated with obesity but not liver disease. Obesity (Silver Spring) 2014;22:83641.

50. Angulo P, George J, Day CP, et al. Serum ferritin levels lack diagnostic accuracy for liver fibrosis in patients with nonalcoholic fatty liver disease. Clin Gastroenterol Hepatol 2014;12:1163-69.

51. Yoneda M, Thomas E, Sumida Y, et al. Clinical usage of serum ferritin to assess liver fibrosis in patients with non-alcoholic fatty liverdisease: Proceed with caution. Hepatol Res 2014;44:E499502.

52. Siddique A, Nelson JE, Aouizerat B, Yeh MM, Kowdley KV. Iron deficiency in patients with nonalcoholic Fatty liver disease is associated with obesity, female gender, and low serum hepcidin. Clin Gastroenterol Hepatol 2014;12:1170-8.

53. Adams, Crawford D, Stuart K, et al. The impact of phlebotomy in nonalcoholic fatty liver disease: A prospective randomized controlled trial. Hepatology 2015;61:1555-64.

54. Beaton MD, Chakrabarti S, Adams PC. Inflammation is not the cause of an elevated serum ferritin in non-alcoholic fatty liver disease. Ann Hepatol 2014;13:353-6.

55. Valenti L, Fracanzani AL, Dongiovanni P, et al. A randomized trial of iron depletion in patients with nonalcoholic fatty liver disease and hyperferritinemia. World J Gastroenterol 2014;20:3002-10.

56. Bai $\mathrm{CH}, \mathrm{Wu}$ MS, Owaga E, Cheng SY, Pan WH, Chang JS. Relationship between hemoglobin levels and risk for suspected non-alcoholic fatty liver in Taiwanese adults. Chin J Physiol 2014;57:286-94.

57. Losekann A, Weston AC, Carli LA, Espindola MB, Pioner SR, Coral GP. Nonalcoholic fatty liver disease in severe obese patients, subjected to bariatric surgery. Arq Gastroenterol 2013;50:285-9.

58. Puri K, Nobili V, Melville K et al. Serum bilirubin level is inversely associated with nonalcoholic steatohepatitis in children. J Pediatr Gastroenterol Nutr 2013;57:114-8.

59. Targher G, Bertolini L, Rodella $S$ et al. Non- alcoholic fatty liver disease is independently associated with an increased prevalence of chronic kidney disease and proliferative/laser-treated retinopathy in type 2 diabetic patients. Diabetologia 2008;51:444-50.

60. Targher G, Chonchol M, Bertolini L et al. Increased risk of CKD among type 2 diabetics with nonalcoholic fatty liver disease. J Am Soc Nephrol 2008;19:1564-70.

61. Targher G, Bertolini L, Rodella S, Lippi G, Zoppini G, Chonchol M. Relationship between kidney function and liver histology in subjects with nonalcoholic steatohepatitis. Clin J Am Soc Nephrol 2010;5:2166-71.

62. Li G, Shi W, Hug H, Chen Y, Liu L, Yin D. Nonalcoholic fatty liver disease associated with impairment of kidney function in nondiabetes population. Biochem Med (Zagreb) 2012;22:92-9.

63. Sirota JC, McFann K, Targher G, Chonchol M, Jalal DI. Association between nonalcoholic liver disease and chronic kidney disease: an ultrasound analysis from NHANES 1988-1994. Am J Nephrol 2012;36:466-71.

64. Targher G, Pichiri I, Zoppini G, Trombetta M, Bonora E. Increased prevalence of chronic kidney disease in patients with Type 1 diabetes and nonalcoholic fatty liver. Diabet Med 2012;29:220-6.

65. Ahn AL, Choi JK, Kim MN et al. Non-alcoholic Fatty Liver Disease and Chronic Kidney Disease in Koreans Aged 50 Years or Older. Korean J Fam Med 2013;34:199-205.

66. El Azeem HA, Khalek el-SA, El-Akabawy H, Naeim H, Khalik HA, Alfifi AA. Association between nonalcoholic fatty liver disease and the incidence of cardiovascular and renal events. J Saudi Heart Assoc 2013;25:239-46.

67. Mikolasevic I, Racki S, Bubic I, Jelic I, Stimac D, Orlic L. Chronic kidney disease and nonalcoholic Fatty liver disease proven by transient elastography. Kidney Blood Press Res 2013;37: 305-10.

68. Li Y, Zhu S, Li B et al. Association between nonalcoholic fatty liver disease and chronic kidney disease in population with prediabetes or diabetes. Int Urol Nephrol 2014;46:1785-91.

69. Machado MV, Gonçalves S, Carepa F, Coutinho J, Costa A, Cortez-Pinto H. Impaired renal function in morbid obese patients with nonalcoholic fatty liver disease. Liver Int 2012;32:241-8.

70. Sesti G, Fiorentino TV, Arturi F, Perticone M, Sciacqua A, Perticone F. Association between noninvasive fibrosis markers and chronic kidney disease among adults with nonalcoholic fatty liver disease. PLoS One 2014;9:e88569.

71. Musso G, Gambino R, Tabibian JH et al. Association of non-alcoholic fatty liver disease with chronic kidney disease: a systematic review and 
meta-analysis. PLoS Med 2014;11:e1001680.

72. Hamad AA, Khalil AA, Connolly V, Ahmed MH. Relationship between non-alcoholic fatty liver disease and kidney function: a communication between two organs that needs further exploration. Arab J Gastroenterol 2012;13:161-5.

73. Orlić L, Mikolasevic I, Bagic Z, Racki S, Stimac D, Milic S. Chronic kidney disease and nonalcoholic Fatty liver disease-is there a link? Gastroenterol Res Pract 2014;2014:847539.

74. Targher G, Byrne CD. Clinical Review: Nonalcoholic fatty liver disease: a novel cardiometabolic risk factor for type 2 diabetes and its complications. J Clin Endocrinol Metab 2013;98:483-95.

75. Bonora E, Targher G. Increased risk of cardiovascular disease and chronic kidney disease in NAFLD. Nat Rev Gastroenterol Hepatol 2012;9:372-81.

76. Bulum T, Kolarić B, Duvnjak M, Duvnjak L. Alkaline phosphatase is independently associated with renal function in normoalbuminuric type 1 diabetic patients. Ren Fail 2014;36:372-7.

77. Xia MF, Lin HD, Li XM et al. Renal functiondependent association of serum uric acid with metabolic syndrome and hepatic fat content in a middle-aged and elderly Chinese population. Clin Exp Pharmacol Physiol 2012;39:930-7.

78. Fussner LA, Charlton MR, Heimbach JK et al. The impact of gender and NASH on chronic kidney disease before and after liver transplantation. Liver Int 2014;34:1259-66.

79. Singal AK, Salameh H, Kuo YF, Wiesner RH. Evolving frequency and outcomes of simultaneous liver kidney transplants based on liver disease etiology. Transplantation 2014;98:216-21.

80. Mikolasevic I, Racki S, Zaputovic L, Lukenda V, Sladoje-Martinovic B, Orlic L. Nonalcoholic Fatty Liver Disease (NAFLD) And Cardiovascular Risk In Renal Transplant Recipients. Kidney Blood Press Res 2014;39:308-14.

81. Mikolasevic I, Racki S, Lukenda V, Milic S, Pavletic-Persic M, Orlic L. Nonalcoholic Fatty liver disease in renal transplant recipients proven by transient elastography. Transplant Proc 2014;46:1347-52.

82. Dunn W, Sanyal AJ, Brunt EM, et al. Modest alcohol consumption is associated with decreased prevalence of steatohepatitis in patients with nonalcoholic fatty liver disease (NAFLD). J Hepatol 2012;57:384-91.

83. Neuschwander-Tetri BA, Clark JM, Bass NM, et al. Clinical, laboratory and histological associations in adults with nonalcoholic fatty liver disease. Hepatology 2010;52:913-24.

84. Sanyal AJ, Chalasani N, Kowdley KV, et al.
Pioglitazone, vitamin E, or placebo for nonalcoholic steatohepatitis. N Engl J Med 2010;362:1675-85.

85. Dixon JB, Bhathal PS, O'Brien PE. Nonalcoholic Fatty Liver Disease: Predictors of Nonalcoholic Steatohepatitis and Liver Fibrosis in the Severely Obese. Gastroenterology 2001;121:91-100.

86. Dunn W, Xu R, Schwimmer JB. Modest wine drinking and decreased prevalence of suspected nonalcoholic fatty liver disease. Hepatology 2008;47:1947-54.

87. Kwon HK, Greenson JK, Conjeevaram HS. Effect of lifetime alcohol consumption on the histological severity of non-alcoholic fatty liver disease. Liver Int 2014;34:129-35.

88. Alkerwi A, Boutsen M, Vaillant M, et al. Alcohol consumption and the prevalence of metabolic syndrome: a meta-analysis of observational studies. Atherosclerosis 2009;204:624-35.

89. Hamaguchi M. Protective effect of alcohol consumption for fatty liver but not metabolic syndrome. World J Gastroenterol 2012;18:156.

90. Guzzo-Merello G, Cobo-Marcos M, GallegoDelgado M, Garcia-Pavia P. Alcoholic cardiomyopathy. World J Cardiol 2014;6:771-81.

91. Walsh CR, Larson MG, Evans JC, et al. Alcohol consumption and risk for congestive heart failure in the Framingham Heart Study. Ann Intern Med 2002;136:181-91.

92. Gonçalves A, Claggett B, Jhund PS, et al. Alcohol consumption and risk of heart failure: the Atherosclerosis Risk in CommunitiesStudy. Eur Heart J 2015;36:939-45.

93. Hillbom M, Numminen H, Juvela S. Recent heavy drinking of alcohol and embolic stroke. Stroke J Cereb Circ 1999;30:2307-12.

94. Thun MJ, Peto R, Lopez AD, et al. Alcohol consumption and mortality among middle-aged and elderly U.S. adults. N Engl J Med 1997;337:170514.

95. Than NN, Newsome PN. A concise review of nonalcoholic fatty liver disease. Atherosclerosis 2015;239:192-202.

96. Voiculescu M, Nanau RM, Neuman MG. Noninvasive biomarkers in non-alcoholic steatohepatitisinduced hepatocellular carcinoma. J Gastrointestin Liver Dis. 2014;23:425-9.

97. Basaranoglu M, Basaranoglu G, Sabuncu T, Sentürk $\mathrm{H}$. Fructose as a key player in the development of fatty liver disease. World $\mathrm{J}$ Gastroenterol 2013;19:1166-72.

98. Stickel F, Buch S, Lau K, et al. Genetic variation in the PNPLA3 gene is associated with alcoholic liver injury in caucasians. Hepatology 2011;53:86-95.

99. Burza MA, Molinaro A, Attilia ML, et al. PNPLA3 I148M (rs738409) genetic variant and age at onset of at-risk alcohol consumption are independent risk 
factors for alcoholic cirrhosis. Liver Int Off $\mathrm{J}$ Int Assoc Study Liver 2014;34:514-20.

100.U.S. Department of Health and Human Services. Summary Health Statistics for U.S. Adults: National Health Interview Survey 2012. Available at http://www.cdc.gov/nchs/data/series/sr_10/sr10_260 .pdf.

101.National Institute on Alcohol Abuse and Alcoholism. What's "at-risk" or "heavy" drinking? Accessed March 2015. http://rethinkingdrinking.niaaa.nih.gov/Is YourDrinki ngPatternRisky/WhatsAtRiskOrHeavyDrinking.asp.

102. Nascimbeni F, Pais R, Bellentani S, et al. From NAFLD in clinical practice to answers from guidelines. J Hepatol 2013;59:859-71.

103. Farrell GC, Chitturi S, Lau GKK, Sollano JD. Guidelines for the assessment and management of non-alcoholic fatty liver disease in the Asia-Pacific region: executive summary. J Gastroenterol Hepatol 2007;22:775-7.

104.Ruhl CE, Everhart JE. Joint effects of body weight and alcohol on elevated serum alanine aminotransferase in the United States population. Clin Gastroenterol Hepatol 2005;3:1260-8.

105. Ascha MS, Hanouneh IA, Lopez R, Tamimi TA-R, Feldstein AF, Zein NN. The incidence and risk factors of hepatocellular carcinoma in patients with nonalcoholic steatohepatitis. Hepatology 2010;51:1972-8.

106.Hajarizadeh B, Grebely J, Dore GJ. Epidemiology and natural history of $\mathrm{HCV}$ infection. Nat Rev Gastroenterol Hepatol 2013;10:553-62.

107.Surdea-Blaga T, Dumitraşcu DL. Depression and anxiety in nonalcoholic steatohepatitis: is there any association? Rom J Intern Med 2011;49:273-80.

108. Weinstein AA, Kallman Price J, Stepanova M et al. Depression in patients with nonalcoholic fatty liver disease and chronic viral hepatitis $\mathrm{B}$ and $\mathrm{C}$.
Psychosomatics 2011;52:127-32.

109.Zelber-Sagi S, Toker S, Armon G et al. Elevated alanine aminotransferase independently predicts new onset of depression in employees undergoing health screening examinations. Psychol Med 2013;43:2603-13.

110.Lee K, Otgonsuren M, Younoszai Z, Mir HM, Younossi ZM. Association of chronic liver disease with depression: a population-based study. Psychosomatics 2013;54:52-9.

111. Mazzone L, Postorino V, De Peppo L et al. Paediatric non-alcoholic Fatty liver disease: impact on patients and mothers' quality of life. Hepat Mon 2013;13:e7871.

112.Stewart KE, Haller DL, Sargeant C, Levenson JL, Puri P, Sanyal AJ. Readiness for behaviour change in non-alcoholic fatty liver disease: implications for multidisciplinary care models. Liver Int 2015;35:936-43.

113. Kerkar N, D'Urso C, Van Nostrand K et al. Psychosocial outcomes for children with nonalcoholic fatty liver disease over time and compared with obese controls. J Pediatr Gastroenterol Nutr 2013;56:77-82.

114.Opel N, Redlich R, Grotegerd D et al. Obesity and major depression: Body-mass index (BMI) is associated with a severe course of disease and specific neurostructural alterations. Psychoneuroendocrinology 2015;51:219-26.

115. Youssef NA, Abdelmalek MF, Binks $M$ et al. Associations of depression, anxiety and antidepressants with histological severity of nonalcoholic fatty liver disease. Liver Int 2013;33:1062-70.

116.Cláudio Nunes-Alves. Modifying the gut to treat liver diseases. Nature Reviews Microbiology 2015;13:8:458-469. 